\title{
PERU E BRASIL: EXPERIÊNCIAS NO MUNDO ACADÉMICO À LUZ DO MODELO DE SEIS DIMENSÕES CULTURAIS DE HOFSTEDE
}

Laura Pissani é mestranda do Programa de Pós-graduação em Estudos da Linguagem da Pontifícia Universidade Católica do Rio de Janeiro. E-mail: laurapissani@gmail.com

\author{
RESUMO \\ Este relato tem por objetivo fazer uma reflexão \\ sobre as diferenças culturais. Especificamente, \\ sobre as diferenças no mundo académico entre \\ Peru e Brasil: dois países tão próximos \\ geograficamente, porém tão diferentes na \\ organização do mundo académico. Neste texto, \\ serão analisadas minhas experiências em ambos os \\ países (no Peru como aluna local e no Brasil como \\ aluna estrangeira) à luz do modelo de seis \\ dimensões proposto por Geert \\ Hofstede, focando na dimensão Power \\ distance index.
}

\begin{abstract}
The purpose of this essay is to make the reader think about cultural differences. Specifically about the differences in the academic world between Brazil and Peru: two countries that are close geographically, but very different in the organization of the academic world. In this text, my experiences in both countries (in Peru as a local student and in Brazil as a foreign student) will be analyzed at the light of the model of six dimensions postulated by Geert Hofstede, focusing on the dimension called Power distance index.
\end{abstract}

No ano 2010, enquanto cursava a graduação em Linguística, já tinha decidido fazer meu mestrado no Brasil. Com muita antecedência, comecei pelo que achei que era o fundamental: aprender a língua do país, o português. Já tinha tido contato com o português, e adorava a língua, os sons e o jeito dos brasileiros de falar, então mais do que um dever, foi para mim um prazer.

O segundo passo foi visitar o Brasil antes de me aventurar a iniciar uma experiência de longo prazo. Achei que seria boa ideia conhecer o país antes de tomar uma decisão, por isso, fui por um mês e amei. Quando voltei ao Peru, comecei a busca de programas de pós-graduação até achar opções que me interessassem academicamente. Assim, depois de muito, cheguei até minha atual instituição de ensino.

Estar no Brasil como turista é extremamente diferente do que estar como residente. Para mim, morar no Brasil tem sido uma experiência totalmente diferente ao que eu estava acostumada no meu país, o Peru. Possivelmente, se alguém pensa no Peru, pode imaginar que não é muito diferente em relação ao Brasil por serem países vizinhos. Certamente, é assim em alguns aspectos, porém se analisamos o mundo acadêmico, podemos achar algumas diferenças significativas.

Baseado em uma extensa pesquisa, Geerts Hofstede et al. (2011) propõem um modelo de seis dimensões culturais para descrever as preferências de um país e como ele se distingue dos outros: Power distance, Uncertainty avoidance,

Masculinity/femininity, Indulgence/restrain, Individualism/collectivism e Long/short term orientation. $\mathrm{O}$ modelo analisa os países como um todo, e não aos indivíduos particulares. 
Comparar o Peru e o Brasil à luz do modelo de seis dimensões de Hofstede oferece a possibilidade de se focar em aspectos ('dimensões', na terminologia de Hofstede) específicos e relevantes. Desse modo, permite perceber que ambos os países podem ser semelhantes na maioria de dimensões, porém algumas delas podem evidenciar aquelas pequenas diferenças que não são tão obvias para quem não conhece em profundidade os mencionados países. Neste relato, focarei na dimensão que, em minha opinião, resulta mais produtiva para mostrar os contrastes culturais entre o Peru e o Brasil: Power distance index (PDI).

A dimensão Power distance index (PDI) se refere ao grau em que as pessoas com menos poder estão cientes e aceitam a desigualdade de poder na sociedade. Uma sociedade com alto PDI mostraria que a desigualdade de poder é um fato e que ele é aceito pela sociedade.

Segundo os dados coletados por Hofstede et al. (Hofstede, 2015), o Brasil apresenta um índice de 69/100, um índice alto que indicaria que os brasileiros acreditam em uma sociedade hierárquica e respeitam às autoridades. O PDI também se aplica no campo familiar e indicaria que os brasileiros respeitam às pessoas mais velhas e cuidam dos seus pais adultos. Segundo a mesma fonte, o Peru tem um PDI muito similar de 64/100, também alto (Hofstede, 2015).

O PDI é aplicado em muitos contextos. No caso do Brasil, certamente, existem muitas leis que beneficiam aos idosos, assim como muitas vantagens para eles como a isenção da taxa de transporte, alta porcentagem de assentos reservados nos ônibus públicos e outras entidades do governo, filas especiais no caixa do supermercado e bancos, bem como atenção preferencial em outros estabelecimentos.

No caso do Peru, o respeito pelo idoso é também um fato. Existem leis respaldadas pelo governo que auxiliam ao idoso, existem também filas preferenciais nos estabelecimentos públicos e privados e sempre dois assentos preferenciais em todos os ônibus.

Neste relato, pretendo me focar nas diferenças mais do que nas semelhanças, especialmente naquelas diferenças que mais chamaram minha atenção. Estudei na maior universidade do Peru e a mais antiga da América Latina, uma entidade prestigiosa e pública, portanto, mantém certas formalidades e metodologias que podem ser diferentes de outras universidades peruanas, especialmente das privadas.

Uma aula (na faculdade) típica no Peru se desenvolve em uma sala que pode ser enorme (se for para disciplinas gerais, matemática geral) ou pequena (se for para disciplinas específicas, morfossintaxes II), nas salas pequenas há um número exato de cadeiras que permanecem em seu lugar e nunca são arranjadas em forma de meia lua ou em círculos para aproximar aos alunos e professores.

A formalidade e a hierarquia são muito evidentes durante o desenvolvimento da aula. Alguns professores pretendem marcar sua superioridade mais do que outros. Em primeiro lugar, alguns professores valoram mais a pontualidade, sempre existe aquela 
professora que chega 5 minutos antes da aula, espera a hora exata do início da aula e fecha a porta, ninguém entra na sala após a hora do início e, além disso, leva um 0 (zero) no dia. Mas também, há outros professores que não se importam muito com os horários, possivelmente, porque eles não são muito pontoais também.

Além do mais, a sala de aula não é um lugar para discutir ou dialogar (em aulas regulares) é um lugar para escutar ao professor, ele planeja um tópico para a aula (segundo o cronograma) é o apresenta para os alunos em forma de discurso. No final, o professor pergunta se alguém tem dúvidas e, claramente, ninguém tem.

Durante a aula não é muito frequente os alunos falarem. Para avaliar a habilidade discursiva dos alunos e sua responsabilidade e seguimento das aulas e leitura dos textos designados, os professores pegam a lista e chamam pelo sobrenome (nunca o nome só, sempre usando ou o sobrenome ou o nome completo) a cinco alunos aleatoriamente, fazem uma questão e colocam o grau.

Os alunos também preparam seminários, fazem apresentações e vão ao quadro e apresentam textos lidos e preparam apresentações em slides, os professores fazem perguntas e, às vezes, os colegas podem discutir.

Durante o transcurso do semestre, a relação entre o professor e o aluno é estritamente académica, é raro conhecer a vida pessoal de um professor. Só sabemos seu sobrenome e sua carreira profissional.

Também, é uma regra conhecida que durante a aula, está proibido comer, só beber é possível, mas se alguém precisa comer, deve sair da sala, terminar seu sanduiche e voltar. Além disso, os alunos devem manter a compostura dentro da sala, ninguém deve tirar os sapatos durante a aula, por exemplo.

No final de cada disciplina, além do teste, os alunos devem apresentar um trabalho de fim de curso designado pelo professor e entregue na data imposta pelo professor sem lugar a prorrogação nem exceções.

Por fim, ao término do semestre os alunos recebem sem muita demora os graus, no máximo alguns dias depois do término das aulas, e os graus não podem ser modificados posteriormente (exceto por erro de digitação).

Depois de 5 anos de curso e de mais um ano dedicado à dissertação, comecei minha aventura académica no Brasil. Minha aventura começou com longos processos seletivos em várias instituições de ensino superior das quais eu gostei. Foi um longo processo (6 meses aproximadamente) com só três atividades (prova de conhecimentos, prova de língua e entrevista) ao longo desse período. Mesmo assim, tive que chegar seis meses antes do início do mestrado para me candidatar, então cheguei com muitas dúvidas e sem certeza de ser recebida.

Felizmente, foi aceita e tudo deu certo, e até foi muito melhor do que eu esperava. Ingressei à minha atual IES e recebi uma bolsa de fomento. Assim que iniciaram as aulas na faculdade, houve um importante congresso e os organizadores nos recomendaram assistir. 
Ao termino das palestras do dia, eram oferecidas atividades diárias para os assistentes ao congresso, especialmente para os participantes internacionais, para se integrarem e conhecerem a cidade. Decidi me juntar, e fui com eles em algumas das atividades propostas. Uma das primeiras atividades foi ir a um barzinho no Arpoador.

Eram umas $21 \mathrm{~h}$, os professores, alunos, palestrantes, ouvintes, locais, convidados, velhos, novos, graduandos, mestrandos, doutorandos, todo mundo começou a chegar, quase todos pediam cerveja, bebiam e conversavam muito, riam, faziam brincadeiras como se fossem amigos de sempre, e todos falavam da noite anterior (acho que tinham ido a uma boate em Lapa, no centro da cidade). Toda aquela cena de professores e alunos, sem hierarquia, bebendo cerveja e conversando na mesma mesa me deixou surpresa. Nunca tinha visto nada similar nas minhas experiências prévias. Foi meu primeiro choque cultural, sem dúvida, muito divertido.

Uma sala de aula típica no mestrado, tanto na minha instituição como em outras IES no Estado do Rio de Janeiro (atualmente, curso disciplinas como aluna especial em outras IES), nunca é calma nem silenciosa, é geralmente cheia de discussão, debate e trocas enérgicas de ideias. Os professores abrem perguntas e os alunos rapidamente respondem e com muito entusiasmo (quando é uma pergunta de opinião, já em perguntas de dados exatos não há tanto ânimo por responder). Há momentos em que as vozes dos alunos e do professor se superpõem e não dá mais para distinguir quem é quem. No Brasil, as pessoas devem falar e competir com as outras vozes, quem fala mais alto é escutado.

Na hora dos seminários, os alunos são em geral muito confidentes, sempre falam muito relaxados, como se estivessem conversando, não existem nervos nem pressão por terem de falar em público.

No final do semestre, ou até semanas depois, os trabalhos são indicados e as instruções são dadas, bem como a data de entrega, que é geralmente um mês após o último dia de aula. Porém, pode existir, se fundamentada, uma possibilidade de prorrogação. $\mathrm{O}$ aluno solicita e justifica a necessidade de prazo extra, e o professor coloca grau incompleto até a data combinada, normalmente são dois meses após a data inicial. Mas em fim, no Brasil, há uma flexibilidade enorme em relação às datas em geral.

Outras experiências e práticas acadêmicas existem na vida universitária brasileira que a faz diferente da peruana e, possivelmente, de muitas outras. Existe aquele ritual do calouro, onde alunos que acabam de ingressar na faculdade pintam seu corpo imitando fantasias e seguem instruções de estudantes mais velhos para fazer diferentes atividades. Pessoalmente, não conheço profundamente aquele ritual, porém já vi calouros pintados chorando, pedindo dinheiro nas ruas e subindo aos ônibus e proibidos de sentar e obrigados a cantar animadamente e repetir o que for indicado por um estudante antigo. Nunca presenciei nada parecido.

Por fim, o vivenciado nesses anos mostra que a distância de poder entre um aluno peruano e seu professor é muito maior do que a distância que existe entre um aluno brasileiro e seu professor. O ambiente académico brasileiro, em geral, é muito mais 
descontraído e com menos regras do que o peruano. Portanto, ao contrário do assinalado pela pesquisa de Hofstede et al. (2011), as observações aqui feitas sugerem que o PDI seja muito maior no Peru do que no Brasil, pelo menos no nível educativo.

Resta refletir e descobrir como as diferenças assinaladas afetam os resultados académicos dos alunos de cada país, assim como o sentir dos alunos que mudam de ambiente académico e até que ponto aquilo pode ou não influenciar seu desempenho. $\mathrm{O}$ presente relato não pretende ser mais do que uma observação dos diferentes entornos vivenciados, motivando futuras pesquisas sobre como o aspecto sociocultural pode ou não repercutir nos frutos acadêmicos desses países.

Finalmente, embora tenha sido para mim uma mudança acadêmica muito grande e no início eu tenha sentido um grande choque cultural, estou muito contente de poder viver esta nova experiência e muito satisfeita com o que estou experimentando.

\section{Referências}

HOFSTEDE, Geerts. Dimensionalizing Cultures: The Hofstede Model in Context. Online Readings in Psychology and Culture, The Berkeley Electronic Press, 2011.

HOFSTEDE, Geerts et al. What about Brazil? Disponível em: <http://geerthofstede.com/national-culture.html>. Acesso em: 16 de outubro de 2015.

HOFSTEDE, Geerts et al. National Culture. Disponível em: <http://geerthofstede.com/brazil.html>. Acesso em: 16 de outubro de 2015. 